\title{
PEMERTAHANAN BAHASA JAWA \\ DALAM PERTUNJUKAN KESENIAN TRADISONAL DI JAWA TENGAH
}

\author{
Hari Bakti Mardikantoro \\ FBS Universitas Negeri Semarang \\ email: haribaktim@mail.unnes.ac,id
}

\begin{abstract}
Abstrak
Tujuan penelitian ini adalah menentukan bentuk pemertahanan bahasa Jawa dan mendeskripsikan faktor sosial budaya yang mempengaruhi pemertahanan bahasa Jawa dalam pertunjukan kesenian tradisional di Jawa Tengah. Data dalam penelitian ini dijaring dengan menggunakan metode simak. Analisis data dilakukan melalui dua prosedur, yaitu (1) analisis selama proses pengumpulan data dan (2) analisis setelah pengumpulan data. Hasil penelitian menunjukkan bahwa bentuk pemertahanan bahasa Jawa dalam pertunjukkan kesenian tradisional di Jawa Tengah meliputi bentuk prakata, tembang, doa, dan pantun. Faktor penyebab pemertahanan bahasa Jawa dalam pertunjukkan kesenian tradisonal di Jawa Tengah yakni upaya menjunjung tinggi budaya Jawa, daerah tempat tinggal/pertunjukan, keselarasann dengan gerak/tari dan musik/gamelan.
\end{abstract}

Kata kunci: pemertahanan bahasa Jawa, pertunjukan kesenian tradisional

\section{JAVANESE LANGUAGE MAINTENANCE IN TRADITIONAL ART PERFORMANCES IN CENTRAL JAVA}

\begin{abstract}
This study aims to find out forms of the Javanese language maintenance and to describe socio-cultural factors affecting it in traditional art performances in Central Java. The data were collected through observations. The data analysis procedureincluded (1) the analysis during thedata collectionprocess and (2) the analysis after the data collection. The results of the study reveal that the forms of the Javanese language maintenance includeforewords, songs, prayers, and quatrains. Meanwhile, the factors affecting the the Javanese language maintenance in traditional art performances in Central Java include efforts to uphold the Javanese culture, areas of residence/performance, and harmony with movements/dances and music/gamelan.
\end{abstract}

Keywords: Javanese language maintenance, traditional art performances,

\section{PENDAHULUAN}

Dalam realitas berbahasa, bahasa tidak bisa dilepaskan dengan faktor sosial dan budaya masyarakat penuturnya. Oleh karena itu, perwujudan suatu bahasa sangat dipengaruhi oleh latar belakang sosial budaya masyarakat penutur bahasa tersebut. Hal ini sejalan dengan apa yang disampaikan oleh Pastika (2005:103) bahwa peran bahasa sangat dominan dalam kehidupan manusia karena bahasa tidak hanya menjadi bagian dari kebudayaan manusia, tetapi juga menjadi penentu dari perkembangan kebudayaan itu sendiri.

Dengan demikian, pemakaian bahasa tidak hanya ditentukan oleh faktor linguistik saja, melainkan juga faktor-faktor nonlinguitsik. Adapun faktor nonlinguistik yang berpengaruh dalam pemakaian bahasa antara lain faktor sosial dan fak- 
tor situasional (Suwito, 1985:23). Adanya kedua faktor tersebut dalam pemakaian bahasa akan menimbulkan variasi bahasa, yaitu bentuk-bentuk bagian atau variasi dalam bahasa yang masing-masing memiliki pola-pola yang menyerupai pola umum bahasa induknya (Poedjosoedarmo, 1976:2).

Pemakaian bahasa dalam suatu masyarakat tutur tidaklah monolitis melainkan variatif. Hal ini menyebabkan dalam suatu masyarakat tutur hampir tidak ada penutur yang monolingual. Para penutur bahasa biasanya akan menguasai lebih dari satu bahasa. Apabila dua bahasa atau lebih digunakan secara bergantian oleh penutur yang sama, maka bahasa tersebut dalam keadaan saling kontak. Kontak bahasa terjadi dalam situasi konteks sosial, yaitu situasi ketika seseorang sedang belajar bahasa kedua dalam masyarakat tersebut. Adapun kedwibahasaan diartikan sebagai pemakaian dua bahasa atau lebih oleh seorang penutur. Kontak bahasa cenderung kepada gejala bahasa (langue), sedangkan kedwibahasaan lebih cenderung sebagai gejala tutur (parole). Dengan demikian, kedwibahasaan terjadi sebagai akibat adanya kontak bahasa.

Dalam situasi diglosia yang baik masing-masing bahasa mempunyai ranah pemakaian. Namun, menurut Fishman (Sumarsono dan Partana 2002:199), jika diglosia itu bocor, bahasa yang satu merambah atau merembes ke ranah penggunaan bahasa yang lain. Akibatnya, bahasa yang disebut terakhir ini kemungkinan terdesak penggunaannya. Hal ini dapat menyebabkan pergeseran bahasa karena dalam banyak hal bahasa yang semula dikuasai tidak lagi dipakai. Apabila diglosia itu tidak bocor dan tiap bahasa tetap bertahan pada posisi ranah masing-masing, tidak ada satu bahasa pun yang bergeser atau punah. Masing-masing bahasa akan mempertahankan diri. Seperti halnya pergeseran bahasa, pemertahanan bahasa ini pun bergantung pada banyak faktor, seperti ekonomi, agama, dan politik. Dalam pemertahanan bahasa, suatu guyup secara kolektif menentukan untuk melanjutkan memakai bahasa yang sudah biasa dipakai. Konsep mengenai pemertahanan bahasa lebih berkaitan dengan prestise suatu bahasa di mata masyarakat pendukungnya.

Bahasa Jawa di mata masyarakat Jawa merupakan bahasa ibu yang sekaligus juga sebagai bahasa sehari-hari untuk berkomunikasi. Keberadaan bahasa ini, seperti halnya bahasa daerah lain di Indonesia mulai terhambat oleh bahasa Indonesia yang sudah dianggap sebagai bahasa nasional. Dalam komunikasi sehari-hari pun, bahasa Jawa sudah mulai ditinggalkan oleh para penuturnya, meskipun sama-sama berkomunikasi dengan penutur Jawa. Orang cenderung menggunakan bahasa Indonesia yang dianggap lebih prestise. Dengan demikian telah terjadi pergeseran bahasa, bahkan kalau hal seperti ini terus terjadi secara turun-temurun tidak menutup kemungkinan akan terjadi kepunahan bahasa. Hal ini sesuai dengan apa yang diilustrasikan Mbete (2003:14-15) bahwa jika di dalam keluarga pertuturan antara orang tua dan anak-anak dalam bahasa lokal semakin jarang apalagi menghilang, ini merupakan tanda serius kematian bahasa. Terlebih lagi jika diikuti dengan menghilangnya budaya dongeng, sirnanya kebiasaan bercerita kepada anak-anak sebelum tidur karena kini sudah diganti dengan maraknya program televisi yang sangat permisif dan media pandang dengar modern lainnya.

Meskipun demikian, tidak selamanya bahasa Jawa ditinggalkan oleh para penuturnya. Ada sekelompok penutur yang tetap setia menggunakan bahasa Jawa dalam berkomunikasi, meskipun mereka juga menguasai bahasa Indonesia. Bahasa Jawa tetap dipakai dalam pertunjukan kesenian tradisional di Jawa Tengah. Bahasa yang dipakai untuk menyampaikan 
pesan-pesan dalam pertunjukan tersebut meliputi bahasa Jawa, bahasa Indonesia, dan mungkin bahasa Arab. Bahasa itulah yang dikuasai oleh masyarakat pelaku kesenian tradisional. Penggunaan bahasa-bahasa tersebut erat berkaitan dengan fungsi bahasa dalam masyarakat penuturnya. Penggunaan bahasa tersebut bisa berupa tuturan atau tembang yang digunakan dalam pertunjukan kesenian tradusional. Dengan demikian, akan ada bahasa yang dipilih untuk menyampaikan pesan dalam kesenian tradisional tersebut.

Dari pengamatan yang peneliti lakukan, pelaku kesenian tadisional di Jawa Tengah cenderung masih menggunakan bahasa Jawa dalam mengekpresikan bentuk keseniannya. Bahasa Jawa masih dipertahankan oleh kelompok pelaku kesenian tradisional di tengah arus globalisasi yang terus-menerus 'menggempur' kehidupan kita. Tuntutan agar kesenian kian mengglobal menyebabkan bahasa yang digunakan juga harus menyesuaikan. Namun dalam dalam konteks kesenian tradisional ternyata para pelaku kesenian masih mempertahankan bahasa Jawa sebagai bentuk ekspresi tuturan yang berhubungan dengan kesenian tersebut. Kesenian tradisional yang masih menggunakan bahasa Jawa dalam mengekspresikan seninya antara lain kuda lumping, kethoprak, wayang orang, dan wayang kulit.

Masalah pemertahanan bahasa memang suatu topik yang menarik untuk diteliti. Paling tidak sudah ada beberapa peneliti yang mengkaji masalah pergeseran dan pemertahanan bahasa tersebut, seperti Lieberson (1972), Dorian (1978), Sumarsono (1993), Smith-Hefner (2009), dan Mardikantoro (2012).

Lieberson (1972) meneliti imigran Prancis yang ada di Kanada. Penelitian itu menunjukkan bahwa bahasa pertama imigran masih mampu bertahan terhadap bahasa Inggris, setidak-tidaknya sampai anak-anak mereka mampu bertahan menjelang usia remaja. Sementara Dorian (1978) mengkaji pemertahanan bahasa Gaelik oleh para petani kecil, pemilik tanah sempit yang hidup dari pertanian dan setara dengan kelas petani di Sutherland. Bertahun-tahun bahasa Inggris diasosiasikan dengan penduduk Lowland yang beradab, sedangkan bahasa Gaelik diasosiasikan dengan penduduk Higland yang kasar dan liar. Dalam perkembangannya bahasa Inggris mulai menggeser bahasa Gaelik, namun sekelompok petani berhasil mempertahankan bahasa Gaelik tetap menjadi bahasa mereka.

Di Indonesia penelitian tentang pergeseran dan pemertahanan bahasa pernah dilakukan oleh Sumarsono (1993). Dalam penelitiannya tentang pemertahanan bahasa Melayu Loloan di Bali, Sumarsono menyimpulkan bahwa secara umum bahasa Melayu Loloan di Bali masih bertahan dan dipertahankan oleh guyub Loloan dalam ranah keluarga yang merupakan ranah paling vital sebagai benteng pemertahanan bahasa. Kemampuan bertahannya bahasa Melayu Loloan ini ditentukan oleh adanya bebarapa faktor internal dan eksternal yang saling mendukung.

Smith-Hefner (2009) meneliti hubungan antara pergeseran bahasa, jenis kelamin, dan ideologi perubahan di Jawa Tengah dan DIY. Dalam penelitian ini dikaji pergeseran bahasa Jawa dari gaya bahasa Jawa formal kepada penggunaan bahasa nasional (bahasa Indonesia) dalam konteks sosial dan dalam bidang pendidikan untuk kaum muda. Fokus kajiannya terletak pada perbedaan jenis kelamin dan sikap bahasa, serta ideologi budaya mengenai hubungan antara laki-laki dan perempuan ke dalam bahasa yang membentuk sikap itu. Pada waktu yang sama, dalam banyak peristiwa 'sosial' anak muda lebih senang menggunakan bahasa Indonesia daripada bahasa Jawa (bandingkan Smith-Hefner 2007, Swastika 2003). Hal ini ditunjukkan dengan banyaknya kaum muda yang menggunakan 
bahasa Jawa untuk komunikasi seharihari ada $16.3 \%$ selama periode itu, sedangkan jumlah yang menggunaan bahasa Indonesia dalam komunikasi sehari-hari meningkat menjadi $38.9 \%$.

Sementara itu, Mardikantoro (2012) meneliti bentuk pergeseran bahasa Jawa masyarakat Samin dalam Ranah Keluarga. Penelitian ini bertujuan mendeskripsikan bentuk pergeseran bahasa Jawa yang digunakan oleh masyarakat Samin dalam ranah keluarga. Hasil penelitian menunjukkan bahwa telah terjadi pergeseran bahasa Jawa yang digunakan oleh masyarakat Samin dari bahasa Jawa ngoko ke bahasa Jawa krama. Bahasa Jawa ngoko yang merupakan ciri khas bahasa Jawa masyarakat Samin digunakan dalam berbagai ranah. Namun sejalan dengan berbagai pengaruh, kini masyarakat Samin tidak lagi menggunakan bahasa Jawa ngoko untuk segala keperluan. Bahasa Jawa ngoko hanya digunakan terbatas pada ranah keluarga dan ketetanggaan yang selalu melibatkan sesama masyarakat Samin. Adapun pada ranah yang lain seperti ranah sosial, pendidikan, dan ranah yang lain, bahasa Jawa ngoko tidak digunakan lagi dan beralih menggunakan bahasa Jawa krama.

Dalam artikel ini dikaji pemertahanan bahasa Jawa dalam pertunjukan kesenian tradisional yang sering ditampilkan masyarakat di Jawa Tengah. Dalam konteks konservasi budaya, bentuk pemertahanan bahasa Jawa ini merupakan upaya yang dilakukan masyarakat dalam mengkonservasi bahasa daerah yang dikhawatirkan makin lama akan makin tergeser. Mengacu pada konteks permasalahan tersebut, ada dua tujuan yang diungkap dalam penelitian ini, yaitu (1) mendekripsikan bentuk pemertahanan bahasa Jawa dalam pertunjukan kesenian tradisional di Jawa Tengah dan (2) menentukan faktor sosial budaya yang mempengaruhi pemertahanan bahasa Jawa dalam pertunjukan kesenian tradisional di Jawa Tengah.

\section{METODE}

Penelitian ini akan menjawab permasalahan pemertahanan bahasa jawa dalam pertunjukan kesenian tradisonal di Jawa Tengah. Dalam kajian ini, selain bentuk pemertahanan bahasa Jawa tentu akan dipertimbangkan faktor sosial budaya yang menyebabkan pemertahanan bahasa Jawa dalam pertunjukan kesenian tradisional di Jawa Tengah. Oleh karena itu, pengkajian masalah ini akan menggunakan pendekatan sosiolingusitik. Pendekatan sosiolinguistik digunakan untuk menganalisis bentuk pemertahanan bahasa Jawa pada pertunjukan kesenian tradisional di Jawa Tengah. Di samping itu, pendekatan sosiolinguistik juga tampak dalam analisis faktor-faktor yang mempengaruhi pemertahanan bahasa Jawa.

Kajian sosiolinguistik melihat fenomena bahasa sebagai fakta sosial yang berhubungan dengan penggunaan bahasa dalam konteks yang sebenarnya (Rokhman, 2003:9). Dengan demikian, kajian sosiolinguistik menyikapi fenomena pemertahanan bahasa sebagai peristiwa komunikasi serta menunjukkan identitas sosial dan budaya peserta tutur. Oleh karena itu, pendekatan sosiolinguistik dalam kajian ini dipusatkan pada model etnografi komunikasi yang dikembangkan oleh Hymes (Rokhman, 2003:9).

Data dalam penelitian ini dijaring dengan menggunakan metode simak. Sehubungan dengan itu, peneliti selalu mengamati setiap penggunaan bahasa. Pengamatan itu, secara khusus, dilaksanakan dengan menerapkan teknik sadap sebagai teknik dasarnya dan diteruskan dengan teknik lanjutan yang berupa teknik simak bebas libat cakap, teknik rekam, dan teknik catat (Sudaryanto 1993:140). Teknik-teknik tersebut digunakan secara komprehensif untuk memperoleh data yang bervariasi. Dengan demikian, dapat dikatakan bahwa penjaringan data dilakukan dengan metode observasi-partisipatif. 
Selain itu, digunakan juga teknik wawancara untuk menggali data sekunder berkaitan dengan alasan pemertahanan bahasa yang digunakan.

Adapun pertunjukan kesenian tradisional yang dijadikan objek penelitian adalah pertunjukan kesenian tradisional di wilayah Provindi Jawa Tengah yakni kesenian kuda lumping (dan pertunjukan lain yang sejenis) seperti Jaran Kepang di Kabupaten Semarang (mewakili Jawa Tengah bagian utara), Sorengan di Kabupaten Magelang (mewakili Jawa Tengah bagian selatan), Ebeg di Kabupaten Banyumas (mewakili Jawa Tengah bagian barat), dan Barongan di Kabupaten Blora (mewakili Jawa Tengah bagian Timur). Pertunjukan kesenian tradisional yang dimaksud adalah pertunjukan kesenian tradisional yang menggunakan bahasa Jawa (bisa berupa berupa tuturan atau nyanyian/tembang).

Data yang berhasil dikumpulkan dari perekaman dan catatan lapangan ditranskripsikan, diklasifikasikan, dan dilakukan penafsiran sementara (Milroy, 1987 dan Strauss et. al, 1990). Untuk menjaga keabsahan data dilakukan dengan cara (a). perpanjangan keikutsertaan, (b). ketekunan pengamatan, (c). trianggulasi, baik trianggulasi sumber data yang diperoleh dari hasil rekaman dan catatan lapangan maupun trianggulasi metode (wawancara dan pengamatan), (d). pemeriksaan data oleh informan, diskusi dengan teman sejawat, dan konsultasi dengan reviewer (Moleong, 1995:175-179, Muhadjir, 1996).

Analisis data dalam penelitian ini lazimnya dilakukan melalui dua prosedur, yaitu (1) analisis selama proses pengumpulan data dan (2) analisis setelah pengumpulan data (Miles dan Huberman 1992:21-25). Prosedur pertama dilakukan dengan langkah (a) reduksi data (data reduction), yaitu melakukan identifikasi pemertahanan bahasa; (b) sajian data dengan matrik; dan (c) pengambilan simpulan/verifikasi yang sifatnya tentatif, baik dengan trianggulasi data maupun dengan trianggulasi teknik pengambilan data.

\section{HASIL DAN PEMBAHASAN Bentuk Pemertahanan Bahasa Jawa}

Bahasa Jawa merupakan bahasa ibu bagi sebagian besar penutur bahasa yang tinggal di wilayah Jawa Tengah. Meskipun keberadaan bahasa Jawa saat ini sudah digantikan bahasa Indonesia dalam beberapa ranah (ranah keluarga, ranah pekerjaan, ranah ketetanggaan), bahasa Jawa masih tetap digunakan sebagai alat komunikasi. Selain itu, bahasa Jawa juga tetap digunakan sebagai alat ekspresi kesenian tradisional di Jawa Tengah.

Dalam kajian ini, ditemukan beberapa bentuk pemertahanan bahasa Jawa dalam pertunjukkan kesenian tradisional di Jawa Tengah. Bentuk itu meliputi prakata, tembang, doa, pembuka pertunjukan.

\section{Prakata}

Prakata adalah pengantar dari ketua atau sesepuh rombongan kesenian tradisional dalam menyampaikan tujuan diselenggarakannya pertunjukan kesenian tradisional ini. Hal ini tentunya berkaitan dengan maksud orang yang punya hajat atau penanggap kesenian tradisional. Dengan demikian, dalam prakata disampaikan tujuan kesenian tradisional dipertunjukkan. Selain itu, ketua atau sesepuh rombongan juga memperkenalkan kesenian tradisional yang dipimpinnya. Dalam bagian ini, biasanya pemimpin rombongan juga melakukan promosi terhadap kesenian tradisional yang dipimpinnya. Data yang dapat diamati:

(1) Wonten ngarsanipun ingkang kagungan dalem, Mbok Surip saha Sri Darkumi sakkluwarga ingkang kawula hurmati, mangga muji syukur dateng ngarsa dalem Allah Subhanahu wataala kula panjenengan sedaya waget angrawuhi menapa ingkang dados undanganipun Mbok Surip 
utawi Sri Darkumi sakkluwarga kanthi wilujeng mboten wonten halangan satunggal punapa-punapa. Pramila ngrawuhaken Panjenegan sedaya ingkang kapernah sepuh kasuwun idi pamucal wilujeng ingkang kapernah nem dipun suwuni pandonganipun .... (Data Jaran Kepang)

'Di hadapan tuan rumah, Bu Surip dan Sri Darkumi sekeluarga yang saya hormati, mari kita selalu memanjatkan puji syukur ke hadapan Allah Subhanahu Wataala, kita dapat menghadiri undangan Bu Surip dan Sri darkumi sekeluarga dengan tidak ada halangan sesuatu apapun. Tujuan mendatangkan Bapak/Ibu sesepuh dalam rangka mohon doa restu...'

Data (1) merupakan tuturan ketua rombongan kesenian tradisional Jaran Kepang Karya Budaya Rukun Santosa (KBRS) Dusun Kalimangli, Desa Karangtengah, Kecamatan Tuntang, Kabupaten Semarang. Dalam prakata tersebut, disampaikan maksud kesenian tradisional itu tampil, yakni ditanggap oleh Mbok Surip dan Ibu Sri Darkumi dalam rangka Aqiqah Ananda Fadhilla Rahmawati. Data (1) disebut prakata karena merupakan data yang berisi tuturan ketua rombongan kesenian tradional jaran kepang mengawali pertunjukan. Dalam prakata tersebut digunakan bahasa Jawa krama. Dalam data tersebut dituturkan maksud tuan rumah mengundang tamu dan pertunjukan jaran kepang.

\section{Tembang}

Dalam pertunjukan kesenian tradisional di Jawa Tengah, tembang dalam bahasa Jawa sering dinyanyikan oleh pelaku kesenian. Tembang ini sebagai variasi gerakan tari dan selalu diiringi gamelan. Dengan variasi seperti ini memunculkan perpaduan yang harmonis antara gerak, tembang, dan musik (gamelan pengiring), sehingga memunculkan keindahan. Data yang bisa diamati:
(2) WALI SANGA

Pencen nyata ana tlatah tanah Jawa Agama Islam pancen nyata le utama Kawit uni sing nyebar para wali sanga

Kang duwe gelar Raden Sahit Sunan Kalijaga

Angone nyebar lewat seni pewayangan

Susah payah akeh pepalang uga ujian Ning nyatane walisanga kesembadan Lan den critane rukun Islam ing pewayangan

Shahadat loro den gambarake Puntadewa

Sholat kang kuat den gamberke Werkudara

Kang bisa ngrampungi perkara cakcakan agama

Nalika lagi perang campuh Bratayudha

Mbayare zakat den ginambar Raden Arjuna

Raden Nakula iku gambarane pasa

Brayat Pendhawa conto laku munggah swarga

(Data Topeng Ireng)

'Memang nyata ada tanah Jawa

Agama Islam memang terbukti yang utama

Dari dulu yang menyebarkan para wali sembilan

Yang punya gelar Raden Sahit Sunan Kalijaga

Cara menyebarkan lewat seni pewayangan

Banyak rintangan dan ujian

Tetapi nyatanya keinginan wali Sembilan kesampian

Menceritakan rukun Islan di pewayangan

Shahadat dua digambarkan Puntadewa 
Sholat yang kuat digambarkan Werkudara

Yang selalu bisa menyelesaikan perkara agama

Ketika sedang perang Bratayuda

Membayar zakat digambarkan raden Arjuna

Raden Nakula itu mengambarkan puasa

Keluarga Pendawa contoh perilaku naik surga'

Tuturan berbahasa Jawa dalam data (2) merupakan tembang yang sering dinyanyikan dalam pertunjukan kesenian tradisonal di Jawa Tengah. Tembang tersebut berjudul Wali Sanga 'Wali Sembilan', yakni sebutan untuk kelompok penyebar agama Islam di tanah Jawa yang berjumlah sembilan. Tembang tersebut dinyanyikan oleh sinden dan diringi musik/gamelan. Dengan perpaduan tari, tembang, dan musik/gamelan, pertunjukan itu menjadi menarik dan enak ditonton. Tembang dalam data (2) tersebut dinyanyikan kelompok kesenian tradisional Topeng Ireng dari Kabupaten Magelang.

\section{Doa}

Doa merupakan permohonan (harapan, permintaan, pujian) kepada Tuhan. Sebagai manusia yang beragama dan percaya akan adanya Tuhan, manusia wajib berdoa. Dalam doa, ada harapan, permintaan, dan pujian manusia kepada Tuhannya. Para pelaku kesenian tradisional yang sedang mempertujukkan keahliannya dakam kesenian tradisonal tidak lupa juga memanjatkan doa kepada Tuhan dengan harapan diberi perlindungan dan kelancaran dalam melaukan pertunjukan kesenian tradisional. Doa ini sering dipanjatkan di awal (terutama) dan di akhir pertunjukan oleh orang yang dianggap paling senior dalam kelompok itu. Data yang dapat diamati:

(3) Allahumma Sholli Wa Salim 'Alaa
Sayyidina wa maulana Muhammadin Adaddama Fil 'Ilmillahi Sholata Daimata Bidawamin Mulkillahi

Tamba ati iku ana limang perkara Kaping siji maca Qur'an sak maknane Kapindone wong kang sholeh kumpulana

Kaping telu sholat wengi lakonana Kaping papat weteng ira ngelehana Kaping lima dzikir wengi ingkang suwe

Sopo wonge saben wengi bisa nglakoni Insya Allah Gusti Allah nyembadani Kakang kakang pada plesir (maring endi yayi)

Tuku dhawet, dhawete Banjarnegara Seger adhem legi

(apa iya)

Dhawet ayu, dhawete Banjarnegara

Gathot kaca pringgondani

Ana petruk irunge dawa

Wis semayan aja mblenjani

Ora kepethuk atine gela (Data Ebeg)

'Obat hati itu ada lima perka

Yang pertama baca Qur'an dan maknanya

Yang kedua orang sholeh diajak bergaul

Yang ketiga sholat malam laksanakan Yang keempat jangan makan berlebihan

Yang kelima dzikir malam laksanakan dengan khusuk

Siapa orang yang bisa melaksanakan setiap malam

Insya Allah Gusti Allah mengabulkan

Mas-mas ayo tamasya

(ke manambak)

Beli dawet, dawet Banjarnegara

Segar, dingin, manis

(apa betul)

Dawet ayu, dawet Banjarnegara

Gathot Kaca Pringgodani

Ada Petruk hidungnya penjang Sudah berjanji tidak mengingkari Tidak bertemu hatinya kecewa' 
(4) Nugraha wilasing wilasanipun Gusti ingkang Maha Agung

Mugi anggung sumanda, wonten ing jiwangga kita

Warading sagung dumadi

(Data Ebeg)

‘Berkat dan belas kasih Tuhan Yang Maha Agung

Semoga selalu bersemayam di jiwa dan raga kita

Merata kepada seluruh ciptaan'

Data (3) dan (4) merupakan doa dalan bahasa Arab dan Jawa. Doa itu muncul dalam di awal dan akhir pertunjukan kesenian tradisonal di Jawa Tengah. Pada data (3) doa diawali dengan sholawat yang berbahasa Arab dan dilanjutkan dengan pujian berbahasa Jawa, bahkan doa tersebut divariasi dengan pujian berupa tembang Tamba Ati yang merupakan pujian versi bahasa Jawa. Adapun data (4) doa disampaikan dalam bahasa Jawa ketika mengawali pertunjukan.

\section{Pantun}

Penggunaan bahasa Jawa dalam pertunjukan kesenian tradisional di Jawa Tengah selain berbentuk tembang, juga ada yang berbentuk pantun. Pantun adalah sebuah bentuk puisi lama yang terdiri atas empat larik dengan rima akhir ab ab. Ciri-ciri pantun adalah (a) tiap bait terdiri dari 4 baris, (b) tiap baris terdiri dari 4 atau 5 kata, (c) sajaknya berbentuk ab ab, (d) baris pertama dan kedua merupakan sampiran, (e) baris ketiga dan keempat merupakan isi. Pantun muncul dalam pertunjukan kesenian tradisional sebagai bentuk variasi dengan tembang. Data yang dapat diamati:

(5) Ana montor mabur

Montor mabur gedhe rodhane

Sampeyan seng cilik dhuwur

Cilik dhuwur gedhe atine.

(Data Barongan)
'Ada pesawat terbang

Pesawat terbang besar rodanya

Anda yang kecil tinggi

Kecil tinggi besar hatinya'

Data (5) merupakan pantun dalam bahasa Jawa yang disampaikan dalam pertunjukan kesenian tradisional. Pantun tersebut disampaikan oleh penyanyi/sinden di sela-sela melantunkan tembang. Kalau dicermati pantun tersebut memenuhi persyaratan sebuah pantun, yakni tiap bait terdiri dari 4 baris, tiap baris terdiri dari 4 atau 5 kata, sajaknya berbentuk ab ab, baris pertama dan kedua merupakan sampiran, baris ketiga dan keempat merupakan isi.

\section{Faktor Penyebab Pemertahanan Bahasa Jawa dalam Pertunjukkan Kesenian Tradisional}

Terjadinya pemertahanan bahasa Jawa pada pertunjukan kesenian tradisional di Jawa tengah tentu ada faktor penyebabnya. Faktor tersebut, antara lain:

\section{Upaya Menjunjung Tinggi Budaya Jawa}

Budaya Jawa merupakan budaya yang melekat pada orang Jawa. Bahkan budaya ini sudah merupakan sikap mental orang Jawa. Sikap mental juga analog dengan sikap hidup, yakni sikap hidup orang Jawa yang menjadi acuan dalam bertindak (bertingkah laku) dalam kehidupan. Istilah demikian serupa dengan pandangan hidup Jawa atau wawasan hidup Jawa. Sikap hidup orang Jawa antara lain dapat dilihat lewat batinnya (Endraswara 2010:43).

Menjunjung tinggi budaya Jawa ini juga sangat terlihat saat Sanggar Barong Risang Guntur Seto Blora pentas. Mereka masih menggunakan alat musik tradisional gamelan dan seorang sinden sebagai pengiring pertunjukan barongan. Data yang dapat diamati:

(6) Buta-buta galak, mlakune lonjaklonjak. 
Hake..hake...hokya..hokyaa....

Apa dayane ora-ora seni barong neng Blora

Yo ngono mas...nek ora dadi ora kontes.

Kontes neng sembarang.

Akeh bocah ayu-ayune mas.

Cah ayu tha mas....

(Data Barongan)

'Raksasa-raksasa kejam, jalannya melonjak-lonjak

Hake..hake...hokya..hokyaa....

Apa daya ada seni Barong di Blora

Ya begitulah mas ... kalau tidak jadi tidak kontes

Kontes di sembarang tempat

Banyak gadis cantik-cantik mas

Gadis cantik ya mas....'

Data (6) merupakan tembang dalam bahasa Jawa yang dinyanyikan kelompok Barong Risang Guntur Seto Blora saat pentas. Walaupun zaman sekarang sudah maju, tetapi para pelaku kesenian tradisional tetap ingin menjunjung tinggi budaya Jawa. Menurut penuturan Bapak Adi, ketua rombongan sekaligus pelatih barongan, dalam pentas barong yang dilakukannya, mereka tidak mau mengganti bahasanya menjadi bahasa Indonesia atau bahasa yang lain. Dalam melatih pemainpemain barongan yang kebanyakan anakanak muda, Bapak Adi tetap menanamkan nilai- nilai Jawa agar budaya Jawa tersebut tidak luntur. Beliau mengajarkan dengan benar budaya dan bahasa Jawa ini kepada anaknya sebagai penerus Sanggar Barong Risang Guntur Seto tersebut agar kesenian Jawa barong tetap hidup.

\section{Daerah Tempat Tinggal/Pertunjukan}

Faktor ini berkaitan dengan tempat pertunjukan kesenian tradisional di daerah-daerah di Jawa Tengah. Kesenian tradisional biasanya dipentaskan di wilayah-wilayah pedesaan yang padat penduduknya dan terbiasa menggunakan bahasa Jawa. Data yang dapat diamati:

\section{(7) ATUR SUGENG}

Atur sugeng dhumateng kang samya dhateng

Amreksani badhan kula wujud cemeng meleng-meleng

Sampun ngantos samiya njinggleng

Mangke mundhak mesengeren

Atur kula dhumateng kang samyo priksa

Ageng alit kakung putri sepuh mudha sedaya

Yen wonten lepat kawula

Nyuwun gunging pangaksama

Kula niki lare ndayakan sedaya

Dereng saget tata lan uda negara sanyata

Sagete mung lunga saba

Ngupadas pangupa jiwa

Sampun cekap kang dados atur kawula Mugi samyo sekecakna lenggah ira sedaya

Sinambi mriksa kawula

Kang rupane mboten tata

(Data Topeng Ireng)

'MENGUCAPKAN SELAMAT

Selamat kepada semua yang hadir

Menyaksikan diri saya berwujud hitam sekali

Jangan sampai semua terpana

Nanti jadi terheran-heran

Ucapan saya kepada semua yang menyaksikan

Besar kecil, laki-laki perempuan, tua muda semua

Jika ada kesalahan mohon dimaafkan

Saya anak kelompok Ndayakan semua Belum bisa berjasa pada Negara

Bisanya hanya pergi bermain

Mencari hiburan hati

Sudah cukup yang saya katakana

Selamat menikmati sambil memperhatikan saya

Yang wajahnya tidak beraturan' 
Data (7) merupakan tembang yang dinyanyikan dalam pementasan kesenian tradisional Topeng Ireng di Magelang. Kesenian tradisional biasanya dipentaskan di desa-desa di wilayah Provinsi Jawa Tengah. Meskipun demikian, bukan berarti kesenian tradisional tidak pernah pentas di daerah perkotaan. Hanya lebih sering pentas di desa-desa. Masyarakat desa cenderung menggunakan bahasa Jawa sebagai bahasa komunikasi seharihari. Oleh karena itu agar masyarakat desa merasa terlibat dan dapat menikmati pementasan kesenian tradisional, kelompok-kelompok kesenian tradisional yang pentas selalu menggunakan bahasa Jawa. Di samping itu, dalam banyak kasus, kelompok-kelompok kesenian tradisional biasanya juga tumbuh dan berkembang di daerah-daerah/desa-desa. Pelaku-pelaku kesenian tradisional juga merupakan masyarakat yang tinggal di desa-desa. Masyarakat desa cenderung menggunakan bahasa Jawa dalam berkomunikasi sehari-hari, sehingga masuk akal apabila kesenian tradisional juga dipentaskan menggunakan bahasa Jawa.

\section{Keselarasan dengan Gerak dan Musik}

Dari hasil wawancara, para informan menyatakan bahwa penggunaan bahasa Jawa sangat selaras dengan gerak dan musik/gamelan pengiringnya. Dengan perpaduan tuturan menggunakan bahasa Jawa, gerak tari, dan musik akan memunculkan keindahan dalam pertunjukan kesenian tradisonal. Data yang dapat diamati:

(8) LARA BRANTA

Adhuh yayi ra lila atiku

Mung amerga ketampek tresnaku

Awan lan bengi sliramu taktunggu

Nanging jawabanmu

Nglarani atiku
Dhuh cah ayu imbangna tresnaku

Ra mung gawe bingunge atiku Urip lan pati among katur sliramu

Dhuh cah ayu kok tegane atimu

Among ati iki ra ana sing nambani Sak liane sliramu pujane ati Katresnan ku ginawa tekane pati Dhuh cah ayu gendhuk nita gantilane ati

Senadyan ta nganggo korban nyawa Ngga dhek nitha ku wes mesti lila (Data Soreng)

\section{'SAKIT ASMARA}

Aduh adik tidak rela hatiku Hanya karena ditolak cintaku Siang dan malam Anda saya tunggu Tetapi jawabanmu menyakitkan hatiku

Duh, gadis cantik terimalah cintaku

Tidak hanya membuat bingung hatiku

Hidup dan mati hanya untukmu Hati ini tidak ada yang menyembuhkan

Selain dirimu pujaan hatiku

Cintaku dibawa sampai mati

Duh gadis cantik tambatan hatiku

Sakit hati ini tidak ada yang menyembuhkan

Selain dirimu pujaan hatiku

Cintaku terbawa sampai mati

Duh gadis cantik tambatan hatiku

Walaupun harus mengorbankannyawa Untuk Adik Nita pasti rela'

Data (8) merupakan tembang yang dinyanyikan oleh kelompok kesenian tradisional di Jawa Tengah. Tembang tersebut dinyanyikan oleh Sinden dan diiringi oleh gamelan yang ditabuh oleh para niyaga. Tembang pada data (8) termasuk tembang yang melankolis, artinya tembang itu biasanya dinyanyikan dengan lembut. Dengan demikian, gerak para pelaku kesenian tradisional juga lembut 
seiring dengan tembangnya. Begitu juga gamelan yang mengiringinya dibunyikan dengan pelan, sehingga muncul perpaduan yang indah antara tembang, gerak dan gamelan. Suasana seperti ini dalam pertunjukan kesenian tradisional biasanya muncul pada awal-awal pertunjukan untuk membangun suasana. Setelah itu, perlahan-lahan gerak/tari, tembang, dan gamelan akan berangsur-angsur cepat dan lebih cepat dan pada puncaknya biasanya ada pemain yang trance/kesurupan.

\section{SIMPULAN}

Berdasarkan hasil dan pembahasan tersebut, dapat disimpulkan beberapa hal sebagai berikut: (1) bentuk pemertahanan bahasa Jawa dalam pertunjukan kesenian tradisional di Jawa tengah meliputi bentuk prakata, tembang, doa, dan pantun dan (2) faktor yang menyebabkan terjadinya pemertahanan bahasa Jawa dalam pertunjukan kesenian tradisional di Jawa Tengah meliputi upaya menjunjung tinggi budaya Jawa, daerah tempat tinggal/pertunjukan, keselaran dengan gerak/tari dan musik/gamelan.

\section{UCAPAN TERIMA KASIH}

Artikel merupakan salah satu luaran penelitian Desentralisasi skim Hibah Fundamental tahun 2015. Oleh karena itu, penulis mengucapkan terima kasih kepada Rektor Universitas Negeri Semarang, Ketua LP2M Unnes, dan para reviewer, yakni Prof. Dr. Etty Soesilowati M.Si. dan Prof. Dr. Soegiyanto M.S. yang telah berkenan menyeleksi, memberi masukan, dan menilai penelitian ini.

\section{DAFTAR PUSTAKA}

Dorian, Nancy. 1978. "The Dying Dialect and The Role of The Schools : East Sutherland Gaelic and Pensylvania Dutch", dalam J. Alatis (ed.), Georgetown University Round Table on Languages and Linguistics 1978.
Washington : Georgetown University Press.

Endraswara, Suwardi. 2010. Falsafah Hidup Jawa. Yogyakarta: Cakrawala.

Lieberson, Stanley. 1972. "Bilingualism in Montreal : a Demographic Analysis" dalam J. Fishman (ed), Advances in The Sociology of Language Volume 2. The Hague: Moauton.

Mardikantoro, Hari Bakti. 2012. "Bentuk Pergeseran Bahasa Jawa Masyarakat Samin dalam Ranah Keluarga" dalam Jurnal Litera Volume 11, Nomor 2, Oktober 2012, hal. $204-215$.

Mbete, Aron Meko. 2003. "Bahasa dan Budaya Lokal Minoritas, Asal-Muasal, Ancaman Kepunahan dan Ancangan Pemberdayaan dalam Kerangka Pola Ilmiah Pokok Kebudayaan Universitas Udayana". Pidato Pengukuhan Jabatan Guru Besar Tetap dalam Bidang Linguistik pada Fakultas Sastra Universitas Udayana, 25 Oktober 2003.

Miles, Matthew B dan A. Michael Huberman. 1992. Analisis Data Kualitatif. Terjemahan Tjetjep Rohendi Rohidi. Jakarta: Universitas Indonesia.

Milroy, Lesley. 1987. Observing and Analysing Natural Language: A Critical Account of Sociolinguistics Method. Oxford: Basill Blacwell.

Moleong, Lexy J. 1995. Metodologi Penelitian Kualitatif. Bandung: PT Remaja Rosdakarya.

Muhadjir, Noeng. 1996. Metodologi Penelitian Kualitatif (Edisi III). Yogyakarta: Rakesarasin.

Pastika, I Wayan. 2005. “Linguistik Kebudayaan: Konsep dan Model" dalam Jurnal Linguistika Vol. 12 No. 22 Maret 2005, hal. $102-112$.

Poedjoseodarmo, Soepomo. 1982. "Kode dan Alih Kode" dalam Jurnal Widyaparwa No. 22 Tahun 1982. Yogyakarta: Balai Penelitian Bahasa, halaman 1-43.

Rokhman, Fathur. 2003. "Pemilihan Bahasa dalam Masyarakat Dwibahasa: 
Kajian Sosiolinguistik di Banyumas". Disertasi. Yogyakarta: UGM Yogyakarta.

Smith-Hefner, Nancy J. 2009. “Language Shift, Gender, and Ideologies of Modernity in Central Java, Indonesia" Journal of Linguistics and Anthropology, Vol 14, Issue 2, pp. 57 -77, ISSN 10551360. Boston: The American Anthropological Assosiation.

Sudaryanto. 1993. Metode dan Aneka Teknik Analisis Bahasa, Pengantar Penelitian
Wahana Kebudayaan secara Linguistis. Yogyakarta: Duta Wacana University Press.

Sumarsono. 1993. Pemertahanan Bahasa Melayu Loloan di Bali. Jakarta: Pusat Pembinaan dan Pengembangan Bahasa.

Sumarsono dan Paina Partana. 2002. Sosiolinguistik. Yogyakarta: Sabda.

Suwito. 1985. Sosiolinguistik, Pengantar Awal. Surakarta: Henary Offset. 